\title{
Value of a specific bradycardic agent in cardiac surgery compared to placebo
}

\author{
K. SKarvan \\ Department of Anesthesia, University of Basel/Kantonsspital, CH-4031 Basel, Switzerland
}

KEY WORDS: Alinidine, open heart surgery, systemic, pulmonary haemodynamics, heart rate, electrocardiogram, plasma levels.

The effects of alinidine on systemic and pulmonary haemodynamics and the ECG were studied in 8 patients early after open heart surgery as a double-blind cross-over comparison between alinidine and placebo. Placebo had no effect on any of the measured variables. Alinidine given as an i.v. bolus (10 mg) followed by an infusion $\left(10 \mathrm{mg} \mathrm{h}^{-1}\right)$ was associated with alinidine plasma levels of $172 \pm 17$ and $114 \pm 13$, respectively, $\left( \pm S E, \mathrm{ng} \mathrm{ml}^{-1}\right)$ and decreased heart rate $(-12 \%)$ and rate-pressure product $(-14 \%)$ in all patients. While stroke volume index tended to increase, there were no changes in arterial, pulmonary and atrial pressures, cardiac index, and systemic and pulmonary vascular resistances. $P R$ and $Q R S$ intervals of the ECG remained unaffected, and the $Q T_{c}$ interval transiently decreased. Alinidine appears to be a suitable drug for control of inappropriate sinus tachycardia in patients with heart disease undergoing surgery.

\section{Introduction}

Heart rate $(\mathrm{HR})$ is one of the major determinants of myocardial oxygen balance ${ }^{[1]}$. The control of HR is an important part of the perioperative haemodynamic management of patients with heart disease, undergoing cardiac or non-cardiac surgery. Patients with aortic or mitral stenosis and patients with coronary artery disease are particularly vulnerable to the adverse effects of sinus tachycardia occurring intraoperatively of during the postoperative period ${ }^{[2]}$. Beta-receptor blocking agents and parasympathomimetic drugs effectively reduce the sinus node rate, but their use in surgical patients may be limited by untoward side-effects. Alinidine appears to be a suitable drug for control on inappropriate sinus tachycardia induced by surgery in patients with heart disease.

However, there are no data on the efficacy and safety of alinidine in this clinical setting. Therefore, we investigated the effects of intravenous (i.v.) alinidine on systemic and pulmonary haemodynamics and the electrocardiogram (ECG) in patients recovering from open heart surgery.

Address for correspondence: Karl Skarvan, MD, Department of Anesthesia, University of Basel/Kantonsspital CH-4031 Basel, Switzerland

\section{Methods}

STUDY PATIENTS

Patients undergoing elective cardiac surgery (aortocoronary bypass operation or valve replacement) who gave written informed consent for the study, which was approved by the institutional human studies committee, were eligible for the study.

The study was carried out in the early postoperative hours. The patients entered the study when the following criteria were fulfilled: (1) sinus rhythm with a rate exceeding 90 beats $\mathrm{min}^{-1}$, (2) functioning atrial and ventricular pacing electrodes in situ, and (3) stable postoperative course. The latter was defined by stable haemodynamics, absence of arrhythmias, urine output $>0.5 \mathrm{ml} \mathrm{kg}{ }^{-1}, \mathrm{P}_{\mathrm{a}} \mathrm{O}_{2}>120 \mathrm{mmHg}$, $\mathrm{P}_{\mathrm{a}} \mathrm{CO}_{2}<45 \mathrm{mmHg}$, blood haemoglobin $>10 \mathrm{~g}$ $100 \mathrm{ml}^{-1}$ rectal temperature $>36 \cdot 5^{\circ} \mathrm{C}$ and blood loss from chest drains $<1 \mathrm{ml} \mathrm{kg}^{-1} \mathrm{~h}^{-1}$. Patients who received beta-blocking agents and/or calcium entry blockers perioperatively, patients with reduced renal function, and patients with atrioventricular conduction abnormalities were excluded.

Seven patients ( 6 male) after an uneventful aortocoronary bypass operation and one patient after aortic valve replacement fulfilled the entry criteria and were included in the study. Their age was $49 \pm 3$ $\mathrm{SE}$, body weight $80 \pm 14 \mathrm{~kg}$, and height $171 \pm 1 \mathrm{~cm}$. 
The study was started on the average $6 \mathrm{~h} 50 \mathrm{~min}$ (range $5 \mathrm{~h} 10 \mathrm{~min}-11 \mathrm{~h} 30 \mathrm{~min}$ ) after the end of operation. One patient was extubated prior to the study, the remaining 7 patients were intubated and ventilated throughout. They were sedated by diazepam $\left(2.5 \mathrm{mg} \mathrm{h}^{-1}\right)$ and morphine $\left(2.5 \mathrm{mg} \mathrm{h}^{-1}\right)$. Their rectal temperature was $37.9 \pm 0.9^{\circ} \mathrm{C}$ at the beginning and $38.2 \pm 0.8^{\circ} \mathrm{C}$ at the end of the study.

During the study 3 patients were receiving a constant rate infusion of nitroglycerin $(33,80$, and $80 \mu \mathrm{g}$ $\min ^{-1}$, respectively) 1 patient was receiving nitroglycerin $\left(120 \mu \mathrm{g} \mathrm{min}^{-1}\right)$, adrenaline $\left(1.2 \mu \mathrm{g} \mathrm{min}^{-1}\right)$ and lidocaine $\left(2 \mathrm{mg} \mathrm{min}^{-1}\right)$. All eight patients completed the study and there were no drop outs.

\section{HAEMODYNAMIC MEASUREMENTS}

Arterial pressure (AP) was measured by means of a $20 \mathrm{~g}$ Teflon ${ }^{\circledR}$ cannula inserted into the radial artery. Right atrial and pulmonary artery pressures (RAP, PAP) were measured by a balloon directed triple lumen Swan-Ganz catheter inserted through the right jugular internal vein into the pulmonary artery. Left atrial pressure (LAP) was measured by a catheter inserted into the left atrium through the right upper pulmonary vein following pericardiotomy. All catheters were connected to pressure transducers (COBE 41-500, COBE Laboratories, Lakewood, $\mathrm{CO})$ with $150 \mathrm{~cm}$ stiff polyethylene tubing. The zero level was adjusted at mid-chest level. The transducers were calibrated with a mercury manometer. A multiple channel recorder (Hellige. Freiburg i. Br., F.R.G.) was used for recording the pressures along with (ECG). Mean pressures $\left(A P_{m}, P P_{m}, R A P\right.$, LAP) were obtained by electronic integration.

Edwards Lab Cardiac Output Computer (Santa Ana, CA, model 93-132-5F) was used for cardiac output $(\mathrm{CO})$ measurements. At end-expiration, 10 $\mathrm{ml}$ of iced $5 \%$ dextrose solution were injected into the proximal port of the triple lumen thermodilution catheter. During the first $10 \mathrm{~min}$ after each bolus injection of the study drug $\mathrm{CO}$ was determined in duplicate, whereas triplicate measurements were performed thereafter.

Cardiac index (CI), stroke volume index (SVI), systemic and pulmonary vascular resistances (SVR, PVR), left ventricular stroke work index (LVSWI) and right ventricular stroke work index (RVSWI) were calculated according to standard formulae ${ }^{[3]}$.

Heart rate (HR) was derived from the ECG. Ratepressure product was calculated as the product of heart rate and peak arterial systolic pressure.

\section{ELECTROCARDIOGRAM}

Leads II and $V_{5}$ of the ECG were recorded simultaneously with the pressures (chart speed $50 \mathrm{~mm} \mathrm{~s}^{-1}$ ) and analyzed for RR, PR, QRS and QT intervals. Each value represents the mean of 5 heart cycles recorded at end-expiration. The rate corrected $\mathrm{QT}_{\mathrm{c}}$ interval was calculated accordingly to the Bazett formula : $\mathrm{QT}_{\mathrm{c}}=\mathrm{QT} / \sqrt{\mathrm{RR}}$. In addition both $\mathrm{ECG}$ leads were analyzed for significant $(\geqslant 1 \mathrm{~mm})$ shifts of the ST segment and changes in the configuration of the $T$ waves. A standard 12-lead ECG was recorded before and after the study.

\section{ALINIDINE PLASMA LEVELS}

Blood samples for alinidine concentration were taken from the indwelling radial artery cannula at the end of both control periods, 2 min after the end of each bolus injection and at the end of each infusion period. The blood samples were immediately heparinized using $0.025 \mathrm{ml}$ Heparin $\mathrm{NOVO}^{\circledR}$.

Plasma samples were prepared by centrifugation $(10 \mathrm{~min}$ at $3000 \times \mathrm{g})$ and kept frozen $\left(-20^{\circ} \mathrm{C}\right)$ until analyzed. The concentration of alinidine in the plasma samples were determined by a radioimmunoassay method ${ }^{[4]}$.

\section{EXPERIMENTAL PROTOCOL}

The study design was a randomized double-blind cross over comparison between alinidine and placebo (Fig. 1).

The first control period of 1 hour served to assess the stability of the haemodynamics and the persistence of the entry criteria. Then $10 \mathrm{ml}$ of saline containing either $10 \mathrm{mg}$ of alinidine or placebo were injected into a separate central venous catheter over $30 \mathrm{~s}$ and an alinidine $\left(10 \mathrm{mg} \mathrm{h}^{-1}\right)$ or placebo infusion was started. The infusion was terminated 60 minutes after the end of the bolus and 60 minutes were allowed for wash out. Then the second bolus dose was injected and the second infusion of alinidine/ placebo was started.

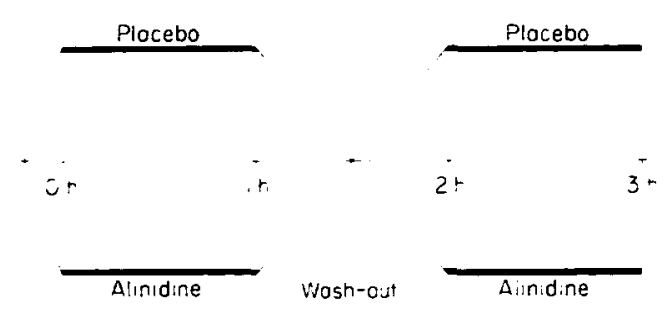

Figure 1 Diagram of the cross-over design of the present study. 
Haemodynamic and ECG measurements were performed at the end of each control period and 2, 4, $6,8,10,20,30$ and $60 \mathrm{~min}$ after each bolus dose.

The test drugs were provided in ampuls containing $10 \mathrm{mg}$ in $2 \mathrm{ml}$ of solvent. Immediately before each experiment the bolus injection and the infusion were prepared by adding $0.9 \% \mathrm{NaCl}$ solution to the content of the original ampul to yield a final concentration of $1 \mathrm{mg} \mathrm{ml} l^{-1}$ and $0.1 \mathrm{mg} \mathrm{ml}^{-1}$ for the bolus injection and the infusion, respectively. An infusion pump (Diginfusa, Schoch, Zürich, Switzerland) was used to deliver the study drug at a constant infusion rate of $1.7 \mathrm{ml} \mathrm{min} \mathrm{m}^{-1}$.

\section{Results}

HAEMODYNAMIC (TABLES 1 AND 2)

The control haemodynamics were characterized by low SVR and increased HR and CI. There were no differences in control values between the alinidine and placebo phase.

Placebo had no effects on any of the measured haemodynamic variables. Alinidine in contrast

Table 1 The effects of alinidinelplacebo on systemic haemodynamics

\begin{tabular}{|c|c|c|c|}
\hline Variable & & $\mathrm{C}$ & $10 \mathrm{~min}$ after bolus \\
\hline $\operatorname{HR}\left(\min { }^{l}\right)$ & $\begin{array}{l}\mathrm{A} \\
\mathrm{P}\end{array}$ & $\begin{array}{l}103 \pm 5 \\
100 \pm 2\end{array}$ & $\left.\begin{array}{r}91 \pm 3 \dagger \\
101 \pm 3\end{array}\right\} * *$ \\
\hline$A P_{m}(m m H g)$ & $\begin{array}{l}A \\
P\end{array}$ & $\begin{array}{l}72 \pm 2 \\
73 \pm 4\end{array}$ & $\begin{array}{l}71 \pm 2 \\
72 \pm 4\end{array}$ \\
\hline $\mathrm{LAP}(\mathrm{mmHg})$ & $\begin{array}{l}A \\
P\end{array}$ & $\begin{array}{l}10 \pm 1 \\
11 \pm 1\end{array}$ & $\begin{array}{l}11 \pm 1 \\
11 \pm 1\end{array}$ \\
\hline $\operatorname{SVI}\left(\mathrm{ml} \mathrm{m}^{-2}\right)$ & $\begin{array}{l}\mathrm{A} \\
\mathrm{P}\end{array}$ & $\begin{array}{l}35 \pm 3 \\
35 \pm 2\end{array}$ & $\begin{array}{l}37 \pm 2 \\
34 \pm 3\end{array}$ \\
\hline $\mathrm{CI}\left(1 \mathrm{~min}{ }^{1} \mathrm{~m}^{-2}\right)$ & $\begin{array}{l}A \\
P\end{array}$ & $\begin{array}{l}3 \cdot 6 \pm 0 \cdot 3 \\
3 \cdot 5 \pm 0 \cdot 3\end{array}$ & $\begin{array}{l}3.4 \pm 0.3 \\
3 \cdot 4 \pm 0.3\end{array}$ \\
\hline SVR (dyn s cm ${ }^{-5}$ ) & $\begin{array}{l}A \\
P\end{array}$ & $\begin{array}{l}757 \pm 91 \\
822 \pm 109\end{array}$ & $\begin{array}{l}786 \pm 77 \\
817 \pm 109\end{array}$ \\
\hline LVSWI $\left(\mathrm{g} \mathrm{m} \mathrm{m}^{2}\right)$ & $\begin{array}{l}A \\
P\end{array}$ & $\begin{array}{l}29 \pm 2 \\
29 \pm 2\end{array}$ & $\begin{array}{l}30 \pm 2 \\
28 \pm 2\end{array}$ \\
\hline $\mathrm{HR} \cdot \mathrm{AP}_{\mathrm{sys}}\left(\mathrm{mmHg} \min { }^{1} 10^{3}\right)$ & $\begin{array}{l}A \\
P\end{array}$ & $\begin{array}{l}12.5 \pm 0.8 \\
11.8 \pm 0.4\end{array}$ & $\left.\begin{array}{l}10.8 \pm 0.6 \pm \\
11.8 \pm 0.4\end{array}\right\} *$ \\
\hline
\end{tabular}

The values are means $\pm S E$. $C=$ control. $A=$ alinidine. $\mathrm{P}=$ placebo. $\mathrm{HR}=$ heart rate. $\mathrm{AP}$ sys $=$ systolic arterial pressure . $A P_{m}=$ mean arterial pressure. $L A P=$ mean left atrial pressure . $\mathrm{SVI}=$ stroke volume index, $\mathrm{CI}=$ cardiac index, $\mathrm{SVR}=$ systemic vascular resistance, $L V S W I=$ left ventricular stroke work index, $\mathrm{HR} \cdot \mathrm{AP}_{\mathrm{sys}}=$ rate-pressure product, $1 \mathrm{mmHg}=0.133 \mathrm{kPa}$. ${ }^{*}=P<0.05$ compared to placebo, ${ }^{* *}=P<0.01$ compared to placebo, $\dagger=P<0.01$ compared to control, $\ddagger=P<0.05$ compared to control.

Table 2 The effects of alinidinelplacebo on pulmonary haemodynamics and right ventricular pump function

\begin{tabular}{|c|c|c|c|}
\hline Variable & & $\mathrm{C}$ & $10 \mathrm{~min}$ after bolus \\
\hline \multirow[t]{2}{*}{$\widehat{\mathrm{RAP}}(\mathrm{mm} \mathrm{Hg})$} & A & $10 \pm 1$ & $10 \pm 1$ \\
\hline & $\mathbf{P}$ & $10 \pm 1$ & $10 \pm 1$ \\
\hline \multirow[t]{2}{*}{$\mathrm{PAP}_{m}(\mathrm{mmHg})$} & A & $19 \pm 2$ & $19 \pm 2$ \\
\hline & $\mathrm{P}$ & $19 \pm 1$ & $19 \pm 1$ \\
\hline \multirow[t]{2}{*}{ PVR (dyn s $\mathrm{cm}^{-5}$ ) } & A & $107 \pm 9$ & $102 \pm 11$ \\
\hline & $\mathrm{P}$ & $102 \pm 15$ & $106 \pm 6$ \\
\hline \multirow[t]{2}{*}{ RVSWI $\left(\mathrm{g} \mathrm{m} \mathrm{m}^{-2}\right)$} & A & $5 \pm 1$ & $4 \pm 1$ \\
\hline & $\mathrm{P}$ & $5 \pm 1$ & $4 \pm 1$ \\
\hline
\end{tabular}

$\mathrm{RAP}=$ mean right atrial pressure, $\mathrm{PAP}=$ mean pulmonary artery pressure, PVR = pulmonary vascular resistance, $\mathrm{RVSWI}=$ right ventricular stroke work index. The values are means $\pm S E, C=$ control, $\mathrm{A}=$ alinidine, $\mathrm{P}=$ placebo. 
caused a consistent decrease in $\mathrm{HR}$ in all patients (Fig. 2). The effect was already present $2 \mathrm{~min}$ after the bolus and was maintained during alinidine infusion $(-9 \%$ to $-12 \%)$. There was a significant correlation between the decrease in HR $(\triangle \mathrm{HR})$ and the control value of $\mathrm{HR}(r=-0.72, P<0.05)$ (Fig. 3$)$. The decrease in $\mathrm{HR}$ was associated with a slight increase in SVI. At $2 \mathrm{~min}$ and $20 \mathrm{~min}$ after the bolus the changes in SVI were significant, at the other measurements, however, only an upward trend $(P<0.07-0 \cdot 1)$ was present. The other haemodynamic variables remained uneffected.

The rate-pressure product decreased by $11 \%$ and $14 \% 2$ and 60 minutes after the bolus, respectively (Fig. 4).

\section{ELECTROCARDIOGRAPHIC INTERVALS (TABLE 3)}

Neither placebo nor alinidine had any effects on PR and QRS intervals. QT interval, however, tended

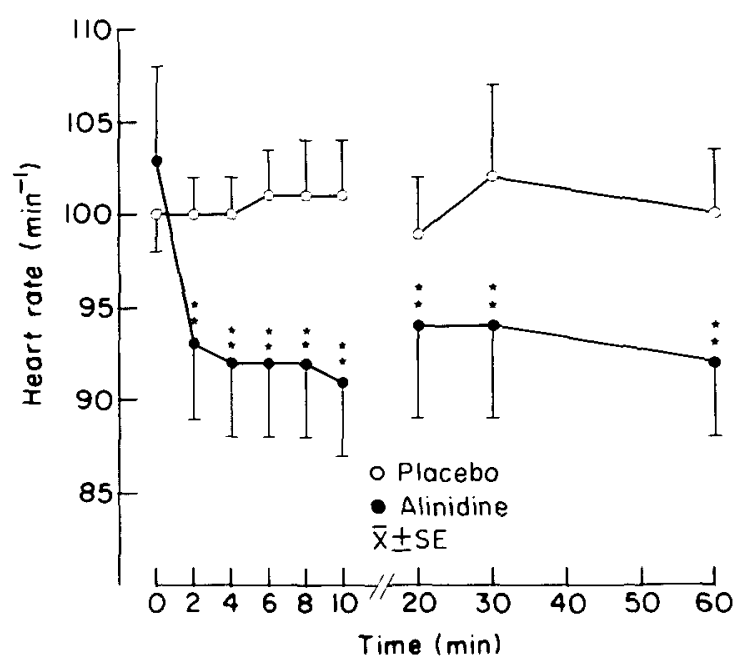

Figure 2 Effects of placebo and alinidine on heart rate. $\dot{z}=P<0.01$ compared to control and placebo.

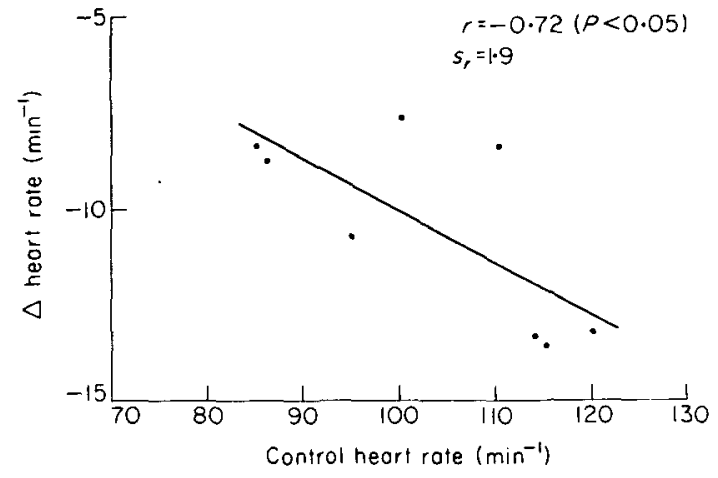

Figure 3 Relation between control heart rate and change in heart rate $(\Delta)$ after $1 \mathrm{~h}$ infusion of $\left(10 \mathrm{mg} \mathrm{h}^{-1}\right)$ alinidine. There is a slight correlation between both variables $(r=-0 \cdot 72)$.

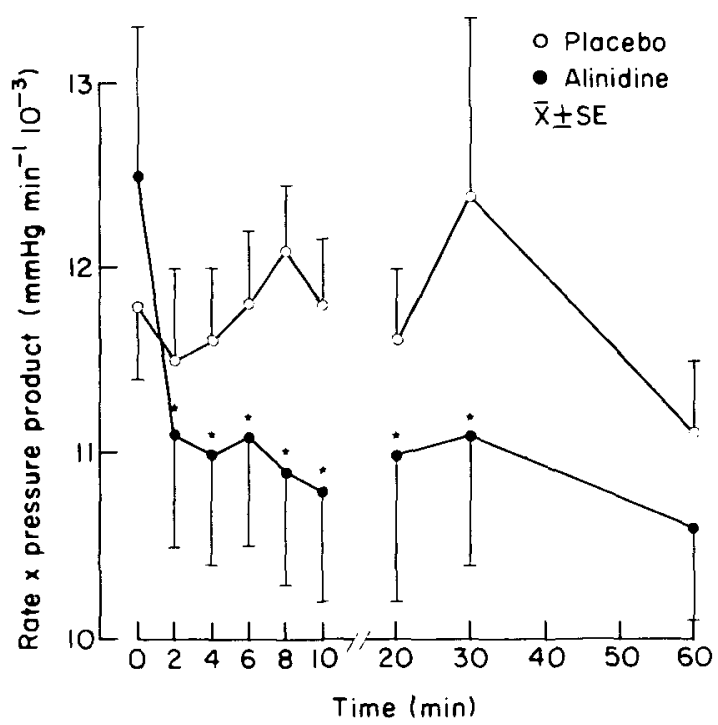

Figure 4 Effects of placebo and alinidine on rate-pressure product ( $=P<0.05$ compared to placebo).

Table 3 The effects of alinidinelplacebo on ECG intervals

\begin{tabular}{lccc}
\hline Variable & & C & 10 min after bolus \\
\hline PR (ms) & A & $164 \pm 7$ & $164 \pm 7$ \\
& P & $163 \pm 7$ & $164 \pm 7$ \\
QRS (ms) & A & $83 \pm 7$ & $82 \pm 6$ \\
& P & $81 \pm 7$ & $84 \pm 6$ \\
QT (ms) & A & $324 \pm 6$ & $333 \pm 3$ \\
& P & $325 \pm 5$ & $330 \pm 3$ \\
QT $_{c}$ (ms) & A & $424 \pm 12$ & $411 \pm 10 \pm$ \\
& P & $420 \pm 9$ & $428 \pm 8$ \\
\hline
\end{tabular}

Values are means $\pm S E$. $A=$ alinidine, $P=$ placebo, $C=$ control. $\ddagger=P<0.05$ compared to control. 
Time after bolus

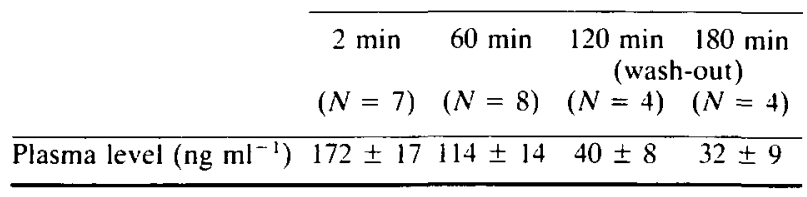

Values are means $\pm \mathrm{SE}$.

to increase during the first 6 min after the alinidine bolus $(P<0.055)$. The rate corrected $\mathrm{QT}_{\mathrm{c}}$ interval decreased 2, 4 and $10 \mathrm{~min}$ after alinidine. No changes in the ST segments were detected and the T-wave morphology also did not change.

\section{ALINIDINE PLASMA LEVELS (TABLE 4 )}

Alinidine plasma level 2 min after the bolus was $171 \pm 17 \mathrm{ng} \mathrm{ml}^{-1}$ and decreased to $114 \pm 13 \mathrm{ng} \mathrm{ml}^{-1}$ at the end of the alinidine infusion. At $1 \mathrm{~h}$ and $2 \mathrm{~h}$ after the cessation of the infusion, alinidine was still present in plasma.

Alinidine plasma levels correlated significantly with the maximal decrease in $\mathrm{HR}(\triangle \mathrm{HR})$ both during the first $10 \mathrm{~min}$ after injection $(r=-0.76$, $P<0.01)$ and at the end of the alinidine infusion $(r=-0.59, P<0.05)$ (Fig. 5). The decrease in plasma level during the following wash-out corresponds to a plasma elimination half-time of $5 \mathrm{~h}$.

There were no side-effects related to alinidine administration. All patients had an uneventful postoperative recovery.

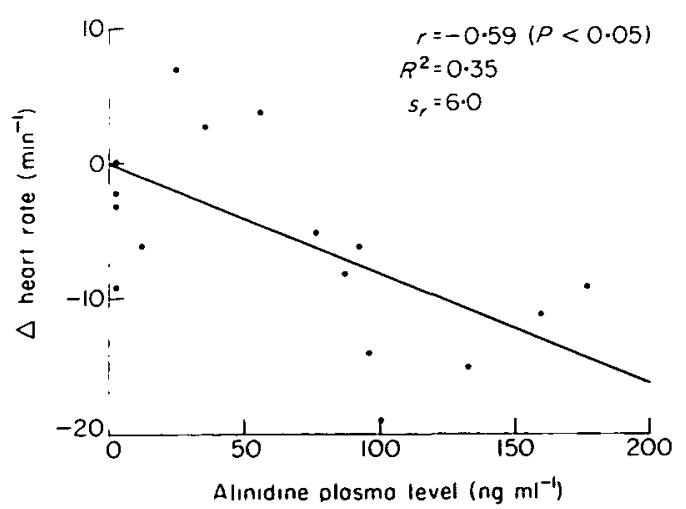

Figure 5 Relation between change in heart rate $(\Delta)$ and alinidine plasma levels after infusion of alinidine. There is a slight correlation between both variables $(r=-0.59)$.

\section{Discussion}

In this study alinidine administered to patients recovering from open heart surgery consistently decreased HR without causing any adverse haemodynamic effects. Placebo, in contrast, had no effects on the haemodynamics. This documents the haemodynamic stability of our patients during the experiment. According to the randomization order, half of the patients were given placebo following an incomplete wash-out of alinidine. The presence of subclinical alinidine levels in these patients had no apparent effect on their response to placebo.

In the early postoperative period the haemodynamic pattern changes with time and, consequently, the effects of alinidine might have been modified by the actual haemodynamic function at the time of its administration.

Prior to administration of alinidine our patients exhibited an uniform haemodynamic pattern of peripheral vasodilation, characterized by low SVR, normal atrial pressures, and increased $\mathrm{Cl}$ associated with a mild sinus tachycardia. Heart failure can, therefore, be excluded as a cause of the tachycardia. Moreover, there were no signs of hypovolaemia, anaemia, cardiac tamponade, or perioperative myocardial infarction, all conditions which may also be responsible for tachycardia. However, all patients had an increased body temperature.

Thus, the increased HR in our patients can be best explained by the combined effects of fever, and high postoperative sympathetic tone with increased levels of circulating catecholamines ${ }^{|s|}$.

The fact that the decrease in $\mathrm{HR}$ after alinidine was not accompanied by any deterioration in the cardiac pump function confirms that the tachycardia was not essential for the maintenance of an adequate flow.

On the other hand, the question arises whether in these patients the reduction in HR due to alinidine was beneficial.

When in a similar group of patients early after aortocoronary bypass operations the HR was 
increased from 87 to 112 beats $\mathrm{min}^{-1}$ by atrial pacing, signs of anaerobic metabolism and decrease in myocardial compliance suggestive of myocardial ischemia occurred $^{[6]}$. In patients after cardiac valve replacement atrial pacing at 128 beats $\mathrm{min}^{-1}$ similarly deteriorated the myocardial oxygen balance ${ }^{[7]}$. Consequently, tachycardia appears to have an unfavorable effect in the early postoperative period and may interfere with the recovery of the ventricular function. This may be particularly important in patients with incomplete revascularization, perioperative myocardial infarction and left ventricular hypertrophy.

Experimental studies demonstrated beneficial effects of slowing the HR in the presence of reduced coronary reserve ${ }^{|8|}$. In animal models with severe coronary artery stenosis alinidine, in a dose which decreased $\mathrm{HR}$ by $25 \%$, caused a marked redistribution of coronary flow in favor of the subendocardium and improved regional myocardial function in the poststenotic area ${ }^{[9,10]}$. Our patients, however, were successfully revascularized and no one had a manifest myocardial ischemia. The question of any benefit from alinidine therapy cannot be answered without special measurements of regional myocardial function and metabolism.

Our findings confirm the previous reports on the negative chronotropic effects of $i . v$. alinidine, which was found to decrease HR both at rest and exercise ${ }^{[11]}$ and to reduce tachycardia due to surgery ${ }^{[12]}$, acute myocardial infarction ${ }^{[13]}$, and dobutamine and nitroprusside infusion ${ }^{[14.15]}$. The dose used in our study (approximately $0.125 \mathrm{mg} \mathrm{kg}^{-1}$ ) was considerably smaller than the doses of $0.3-0.6 \mathrm{mg} \mathrm{kg}^{-1}$ used by other authors. The negative chronotropic effect of alinidine elicited by the bolus injection could be maintained by the subsequent infusion in a dose as low as $2 \mu \mathrm{g} \mathrm{kg}^{-1} \mathrm{~min}^{-1}$. The use of a lower dose can explain both the lack of adverse haemodynamic effects and the rather moderate bradycardic effect found in this study.

Although alinidine decreased $H R$, it had no effect on atrioventicular and intraventricular conduction. This has been previously reported even after considerably higher doses ${ }^{[16]}$ and is of major importance in patients early after cardic surgery, who may have conduction abnormalities. The slight and transient decrease in $\mathrm{QT}_{\mathrm{c}}$ interval appears to result primarily from the slowing of the $H R$ and may reflect a decrease in dispersion of repolarization in ventricular myocardium ${ }^{[17]}$. Such an effect would increase the electrical stability of the heart.
In conclusion the present study clearly reveals that $i . v$. alinidine is effective in reducing postoperative tachycardia without exhibiting any adverse effects on global pump function of the heart. Because of its specific negative chronotropic action alinidine may be preferable to other bradycardic agents for control of inappropriate sinus tachycardia in patients with heart disease undergoing surgery. Further studies, however, will be necessary to determine the optimum dose, mode of administration, and the interactions with other drugs and anethesthics used in the perioperative setting.

I express my appreciation to Boeringer Ingelheim $\mathrm{GmbH}$ for their valuable support of this study. I thank Bioscientia Institute, Ingelheim for alinidine assays, U. Kreuter of Consult AG, Bern for the statistical analysis and Joan Etlinger for excellent secretarial assistance in the preparation of this manuscript.

\section{References}

[1] Marcus ML. The coronary circulation in health and disease. New York: McGraw-Hill, 1983.

[2] Chambers DA. Acquired valvular heart disease. In: Kaplan JA, ed. Cardiac anesthesia. New York: Grune \& Stratton, 1979: 197-240.

[3] Kaplan JA. Hemodynamic monitoring. In Kaplan JA, ed. Cardiac anesthesia. New York: Grune \& Stratton, 1979: 71-115.

[4] Arndts D, Stahle H. Development and quality control of highly sensitive radioimmunoassay for alinidine. $J$ Pharmacol Methods $1981 ; 6: 109-20$.

[5] Kim YD, Jones M. Hanowell ST et al. Changes in peripheral vascular and cardiac sympathetic activity before and after coronary artery bypass surgery: Interrelationships with haemodynamic alterations. Am Heart J 1981; 102: 972-9.

[6] Weisel RD, Burns RJ, Baird RJ et al. A comparison of volume loading and atrial pacing following aortocoronary bypass. Ann Thorac Surg 1983; 36: 332-44.

[7] Wisheart JD. Archie JP. Kirklin JW. Tracy WG. Myocardial blood flow and oxygen consumption in man early after valve replacement. Circulation 1974; 49 : 933-42.

[8] Gross GJ, Lamping KG, Warltier DC, Hardman HF. Effects of three bradycardiac drugs on regional myocardial blood flow and function in areas distal to a total or partial coronary occlusion in dogs. Circulation 1984; 69: 391-9.

[9] Schamhardt HC, Verdouw PD, Saxena PR. Improvement of perfusion and function of ischemic porcine myocardium after reduction of heart rate by alinidine. J. Cardiovasc Pharmaco 1981; 3: 728-38.

[10] Krumpl G. Mayer N, Schneider W, Raberger G. Effects of alinidine on exercise-induced regional contractile dysfunction in dogs. Eur J Pharmacol 1986; 130: $37-46$. 
[11] Löllgen H, Just H, Wollschläger H, Kersting F. Hemodynamic actions of alinidine during exercise in patients with coronary artery disease. Z Kardiol 1981; 70: 425-8.

[12] Fitzal S, Zimper M. Cardiovasular effects of N-allyl clonidine (ST 567, alinidine): a substance with specific bradycardiac action during neuroleptanesthesia in humans. Int J Clin Pharmacol Ther Toxicol 1982; 20: 404-7.

[13] Simoons ML, Hugenholtz PG, Haemodynamic effects of alinidine, a specific sinus node inhibitor, in patients with unstable angina or myocardial infarction. Eur Heart J 1984; 5: 227-32.

[14] Zimpfer M, Khosropour R, Lackner F. Effects of dobutamine on cardiac function in man. Crit Care Med 1982; 10: 367-70.

[15] Zimpfer M, Fitzal S, Semsroth M. Relative roles of heart rate and ventricular stroke volume for the regulation of cardiac output during controlled hypotension with sodium nitroprusside in man. Eur J Clin Invest $1982 ; 12: 9-13$.

[16] Kasper W, Meinertz T, Treese N, Kersting F, Pop T, Jänchen E. Clinical electrophysiological properties of $\mathrm{N}$-Allyl-clonidine (ST 567) in man. J Cardiovasc Pharmacol 1981; 3: 39-47.

[17] Surawicz B, Knoebel SB. Long QT. Good, bad or indifferent? JACC 1984; 4: 398-413. 